\title{
The influence of a maternal diet rich in linoleic acid on brain and retinal docosahexaenoic acid in the rat
}

\author{
BY T. A. B. SANDERS, M. MISTRY AND D. J. NAISMITH \\ Department of Nutrition, Queen Elizabeth College, University of London, \\ Campden Hill Road, London W8 7 AH
}

(Received 1 November 1982 - Accepted 3 August 1983)

\begin{abstract}
1. Female rats were given throughout pregnancy and lactation a semi-synthetic diet, in which the fat was provided entirely by a soft margarine rich in linoleic acid $(18: 2 \omega 6)$ or by mixture of butter and lard, and the influence on the fatty acid composition of fetal and pup brain and retinal phosphoglycerides was studied.

2. The percentage of docosahexaenoic acid $(22: 6 \omega 3)$ was much lower but that of docosapentaenoic acid (22:5 $\omega 6)$ was correspondingly higher in the brains of the day- 22 fetuses and the 21 -d-old pups from the margarine group compared with those from the group given the animal fats. Similar changes were noted in the synaptosomal and retinal phosphoglycerides, being most marked in the ethanolamine phosphoglycerides.

3. The remaining pups from two groups were weaned on day 21 post partum on to the same stock diet that

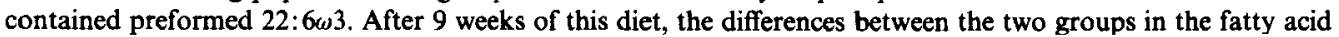
composition of the brain phosphoglycerides were barely discernible. The percentage of $22: 5 \omega 6$ had decreased and had been replaced by $22: 6 \omega 3$.

4. It is concluded that the consequences of consuming a diet rich in linoleic acid and almost devoid of 22:6 63 on brain fatty acid composition deserve consideration in man.
\end{abstract}

Docosahexaenoic acid $(22: 6 \omega 3)$ is found in high amounts in the phosphoglycerides of mammalian brain and retina. Impaired learning ability (Lamptey \& Walker, 1976) and altered retinal function (Wheeler et al. 1975) occur when the percentage of 22:6 33 in these tissues is decreased. Consequently, these workers argue that linolenic acid $(18: 3 \omega 3)$, the dietary precursor of 22:6 33 , should be regarded as an essential nutrient. The percentage of 22:6 33 in brain phosphoglycerides is decreased in the weaning rat pup when the maternal diet is devoid of fat or contains negligible amounts of linolenic acid, usually less than $40 \mathrm{mg} / \mathrm{kg}$ diet (Alling et al. 1972, 1974; Lamptey \& Walker, 1976; Tinoco et al. 1979). In the latter case $22: 6 \omega 3$ was replaced by $22: 5 \omega 6$, a metabolite of linoleic acid $(18: 2 \omega 6)$. The changes induced were most marked when the experimental diet was given to the mother from the time of mating or even earlier. After weaning, the fatty acid composition of the brain phosphoglycerides appears to be more resistant to change (Mohrhauer \& Holman, 1963; Galli et al. 1971).

The relevance of these studies to human nutrition may be questioned because human diets are usually rich in fat and dietary sources of linolenic acid are relatively abundant. However, the extent to which $18: 3 \omega 3$ is converted to $22: 6 \omega 3$ also appears to depend on the relative

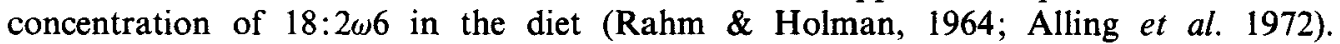
Docosahexaenoic acid can also be obtained preformed through the consumption of animal fats, particularly those from offal and seafood. Most vegetable oils and margarines contain

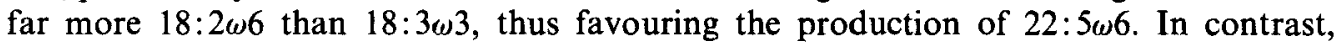
ruminant fats tend to contain approximately equal amounts of 18:2 $\omega 6$ and 18:3 $\omega 3$ (Paul $\&$ Southgate, 1978) thus favouring the production of 22:6 33 . An increased consumption of polyunsaturated fats through the substitution of vegetable oils and margarines rich in $18: 2 \omega 6$ for hard animal fats in the diet has been strongly advocated for the whole community for the prevention of coronary heart disease (Royal College of Physicans/British Cardiac Society, 1976). The possible consequences that this dietary change might have on fetal brain 
composition has not, however, been considered. In view of the practical nature of this problem, we undertook to feed pregnant and lactating rats on a diet in which both the level and fatty acid composition of the dietary fat broadly conformed with these recommendations in order to see whether the balance of $22: 6 \omega 3$ and $22: 5 \omega 6$ in the brain and retinal phosphoglycerides of the pups would be altered, and whether any such change induced would be lasting. A brief account of part of this work has been published (Sanders \& Naismith, 1979).

\section{MATERIALS AND METHODS}

For the pregnancy experiment, litter-mate pairs of virgin rats of the Sprague-Dawley strain weighing $220-230 \mathrm{~g}$ were housed individually in raised stainless-steel cages and a male animal was introduced into each cage. On day 1 of pregnancy, as indicated by the presence of a mating plug, the rats were transferred from a stock diet (CRM; Labsure Animals Foods, Christopher Hill Group Ltd, Poole, Dorset), which provided $74 \mathrm{~J} / \mathrm{kJ}$ metabolizable energy as fat, to one of two experimental diets both providing $402 \mathrm{~J} / \mathrm{kJ}$ metabolizable energy as fat. The experimental diets contained $(\mathrm{g} / \mathrm{kg})$ : fat 200 , casein 200 , maize starch 400 , sucrose 100 , vitamin and mineral mix 60 , solka-floc (cellulose power) $39 \cdot 2$ and DL-methionine; additional vitamin $\mathrm{E}$ was added to the standard vitamin mixture so that $1 \mathrm{~kg}$ diet provided $375 \mathrm{mg}$ of DL- $\alpha$-tocopherol acetate. The fats used were either a soft margarine 'high in polyunsaturates' or a mixture of butter fat and lard $(1: 1, \mathrm{w} / \mathrm{w})$. Total dietary lipids were extracted with $20 \mathrm{vol}$. chloroform-methanol $(2: 1, \mathrm{v} / \mathrm{v})$ and fatty acid methyl esters were prepared by reaction with methanol boron trifluoride reagent for analysis by gas-liquid chromatography (GLC). The animals were allowed access to water and food ad lib. Weight gains and food intakes were recorded. On day 22 of pregnancy eight animals from each group were killed with diethyl ether. The pups, placentas, maternal and fetal livers were dissected and weighed. The fetal brains from each litter were pooled, frozen in liquid nitrogen and stored at $-22^{\circ}$ until analysed.

For the lactation experiment, the animals were mated and transferred to the experimental diets on day 1 of pregnancy. They were housed individually in plastic cages with stainless-steel covers containing a clay bedding material (Litterlab, Ushers). On day 19 of pregnancy, tissue paper was placed inside the cages so that the animals could build a nest. Food intakes were not measured during lactation so as to avoid upsetting the dams. On day 3 post partum, all litters were reduced to eight pups per litter (four males and four females). Litters containing fewer than eight pups were discarded. The stomach contents of the surplus pups were pooled for each experimental group and the fatty acid composition of the milk curd was determined by GLC. On day 21 post partum, two male and two female pups from each litter were killed with diethyl ether and their brains and retinas dissected. The weights of the whole brains and the forebrains were recorded. The remaining pups were transferred to the stock diet on day 21 post partum and were killed 9 weeks later and their forebrains dissected.

The retinas from each litter were collected into $5 \mathrm{ml}$ of an ice-cold solution containing $40 \mathrm{mg}$ EDTA/1 and $8.9 \mathrm{~g}$ sodium chloride/l. The retinas were centrifuged at $3000 \mathrm{~g}$ for $15 \mathrm{~min}$ and the supernatant fraction discarded. Lipids were extracted from the retinal pellet and the phosphoglycerides were separated and analysed by GLC. Forebrains from one male and one female pup from each litter were individually homogenized and the fatty acid composition of the brain phosphoglycerides was determined. The remaining forebrains from each litter were pooled and a synaptosomal-rich fraction was prepared for analysis by discontinuous ultracentrifugation using Ficoll gradients (Morgan et al. 1971).

Lipids were extracted from tissues with 40 vol. chloroform-methanol $(1: 1, \mathrm{v} / \mathrm{v})$ containing $50 \mathrm{mg}$ butylated hydroxytoluene/l. The phosphoglycerides were separated by thin-layer 
chromatography on plates coated with a $0.5 \mathrm{~mm}$ layer of Silca Gel HR and were eluted from the thin-layer chromatography absorbent with chloroform-methanol-water $(5: 5: 1$, by vol.). Fatty acid methyl esters were prepared by transesterification with sodium methoxide in methanol and were analysed by GLC.

GLC analyses were made on a Pye model 204 chromatograph connected to a DP 88 integrator (W. G. Pye, Cambridge). Phosphoglyceride fatty acid methyl esters were separated on a $1.8 \mathrm{~m} \times 4 \mathrm{~mm}$ internal diameter glass column packed with $100 \mathrm{~g}$ Silar $10 \mathrm{C} / \mathrm{kg}$ Gaschrom Q (100-120 mesh). Methyl esters were identified by comparison with mixtures of known composition: authentic standards were available for 4:0, 6:0, 8:0, 10:0, 12:0,

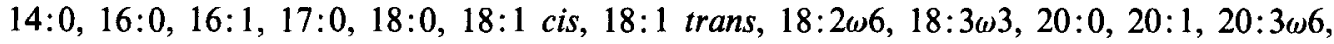

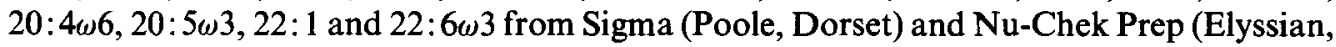

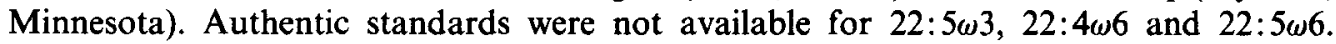
Cod-liver oil was used as a secondary reference standard in order to identify $22: 5 \omega 3$. The identity of $22: 4 \omega 6$ and $22: 5 \omega 6$ was ascertained by calculating their theoretical retention times using the separation factors described by Ackman (1969) and was confirmed by GLC-mass spectroscopy. The analyses for each fraction were made on the same column inside a few days on the same chromatograph which was operated continually in order to minimize between-run variation. The limit for detection in our system was approximately $0.01 \mathrm{wt} \%$ of the total methyl esters injected. The diets and milk curds in addition were analysed on a similar column packed with $100 \mathrm{~g}$ Silar $5 \mathrm{C} / \mathrm{kg}$ Chromosorb WHP (80-100 mesh) in order to separate $16: 1+17: 0$ and $20: 0+18: 2 \omega 6$, which were not separated by the Silar $10 \mathrm{C}$ column, and on a $6 \mathrm{~m} \times 3 \mathrm{~mm}$ internal diameter column packed with $150 \mathrm{~g}$ Silar $10 \mathrm{C} / \mathrm{kg}$ Gaschrom Q(100-120 mesh) to separate cis and trans isomers. The methods used have been described elsewhere in detail (Sanders et al. 1978, 1981; Sanders \& Naismith, $1980 a$; Sanders \& Younger, 1981).

A paired and an unpaired sample $t$ test was used for statistical comparison of the results from the pregnancy and the lactation experiments respectively.

\section{RESULTS}

Food intakes $(\mathrm{g} / \mathrm{d}$ ) were similar in both groups of animals during pregnancy: 18.5 (SE 0.7) in the margarine-fed group compared with 19.4 (SE 1.3) in the butter-lard-fed group. The fatty acid composition of the diets is shown in Table 1 . The daily intakes of $18: 2 \omega 6$ and $18: 3 \omega 3$ were 1.6 and $0.02 \mathrm{~g}$ respectively in the margarine-fed group compared with 0.2 and $0.04 \mathrm{~g}$ in the butter-lard-fed group; these intakes provided, as percentages of the total energy intake, $16 \cdot 2,0 \cdot 2,2 \cdot 3$ and $0 \cdot 4$ respectively. The stock diet provided significant amounts of $18: 2 \omega 6,18: 3 \omega 3,20: 5 \omega 3$ and $22: 6 \omega 3$; as a percentage of the energy intake these were $3 \cdot 5$, $0 \cdot 3,0 \cdot 1$ and $0 \cdot 2$ respectively.

The fatty acid composition of the milk curds (Table 2) was clearly influenced by the nature

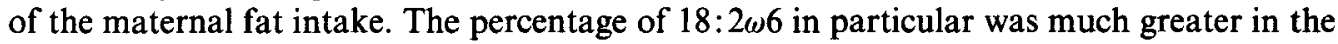
margarine-fed group and the percentages of palmitic $(16: 0)$, stearic $(18: 0)$ and oleic $(18: 1)$ acids were lower. The $\mathrm{C}_{20-22}$ derivatives of the $\omega 6$ and $\omega 3$ series only accounted for a small percentage of the total fatty acids: the total percentage of these fatty acids was 4.84 in the milk curds from the margarine-fed group compared with 1.85 in the butter-lard-fed group;

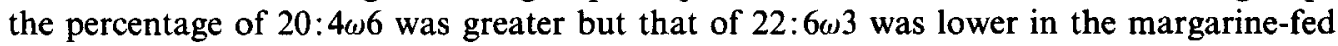
animals.

No differences were found between the two groups in maternal weight gain during pregnancy, the number of pups per litter and the weights of the pups, fetal livers, placentas and maternal livers. Similarly, no differences between the margarine-fed and butter-lard-fed groups respectively were found in fetal brain weights (202 (SE 4.2) mg and 199 (SE 3.6) mg), 
Table 1. The fatty acid composition (wt \% total fatty acids) of the experimental and stock diets

\begin{tabular}{|c|c|c|c|}
\hline Fatty acid & Margarine & Butter-lard & Stock \\
\hline $4: 0$ & 0.0 & 1.6 & 0.0 \\
\hline $6: 0$ & 0.0 & $1 \cdot 2$ & 0.0 \\
\hline $8: 0$ & 0.0 & 0.6 & 0.0 \\
\hline $10: 0$ & 0.0 & $1 \cdot 2$ & 0.0 \\
\hline $12: 0$ & 0.6 & $1 \cdot 3$ & Trace \\
\hline $14: 0$ & 0.8 & $5 \cdot 8$ & 0.8 \\
\hline $14: 1$ & $0 \cdot 0$ & 0.5 & Trace \\
\hline $15: 0$ & Trace & 0.5 & 0.1 \\
\hline $15: 0 \mathrm{Br}+15: 1$ & 0.0 & 0.1 & 0.0 \\
\hline $16: 0$ & $11 \cdot 7$ & $30 \cdot 1$ & $14 \cdot 4$ \\
\hline $16: 1$ & 0.5 & $3 \cdot 1$ & 0.4 \\
\hline $17: 0$ & $0 \cdot 1$ & 0.4 & $0 \cdot 2$ \\
\hline $17: 0 \mathrm{Br}+17: 1$ & 0.0 & 0.3 & 0.0 \\
\hline $18: 0$ & $6 \cdot 4$ & $16 \cdot 2$ & $2 \cdot 0$ \\
\hline $18: 1 \mathrm{cis}$ & $21 \cdot 4$ & $27 \cdot 2$ & $19 \cdot 3$ \\
\hline $18: 1$ trans & $15 \cdot 0$ & $3 \cdot 2$ & 0.0 \\
\hline $18: 2 \omega 6$ & $42 \cdot 4$ & $4 \cdot 8$ & 50.6 \\
\hline $18: 3 \omega 3$ & 0.5 & 0.7 & $4 \cdot 1$ \\
\hline $20: 0$ & 0.4 & 0.4 & 0.2 \\
\hline $20: 1$ & 0.4 & 0.6 & $1 \cdot 3$ \\
\hline $20: 4 \omega 6$ & 0.0 & 0.1 & 0.2 \\
\hline $20: 5 w 3$ & 0.0 & Trace & 1.7 \\
\hline $22: 1$ & 0.0 & 0.0 & $2 \cdot 2$ \\
\hline $22: 5 \omega 3$ & 0.0 & $0 \cdot 1$ & 0.2 \\
\hline $22: 6 \omega 3$ & 0.0 & Trace & $2 \cdot 2$ \\
\hline
\end{tabular}

Table 2. The fatty acid composition (wt \% total fatty acids) of the milk-curd lipids from 3-d-old pups from dams that had been given diets in which the fat was provided by either a soft margarine or a butter-lard mixture

\begin{tabular}{lcc}
\hline \hline Fatty acid & $\begin{array}{c}\text { Margarine } \\
\text { group }\end{array}$ & $\begin{array}{c}\text { Butter-lard } \\
\text { group }\end{array}$ \\
\hline $10: 0$ & $3 \cdot 4$ & $5 \cdot 8$ \\
$12: 0$ & $6 \cdot 3$ & $5 \cdot 2$ \\
$14: 0$ & $5 \cdot 1$ & $7 \cdot 9$ \\
$14: 1$ & $0 \cdot 2$ & $1 \cdot 0$ \\
$16: 0$ & $19 \cdot 0$ & $28 \cdot 1$ \\
$17: 0+16: 1$ & $1 \cdot 8$ & $4 \cdot 2$ \\
$18: 0$ & $3 \cdot 3$ & $6 \cdot 4$ \\
$18: 1$ & $19 \cdot 7$ & $34 \cdot 0$ \\
$18: 2 \omega 6$ & $35 \cdot 0$ & $4 \cdot 0$ \\
$18: 3 \omega 3$ & $0 \cdot 3$ & $0 \cdot 8$ \\
$20: 1$ & $1 \cdot 1$ & $0 \cdot 9$ \\
$20: 2 \omega 6$ & $1 \cdot 1$ & $0 \cdot 2$ \\
$20: 3 \omega 9$ & 0 & Trace \\
$20: 3 w 6$ & $1 \cdot 0$ & $0 \cdot 2$ \\
$20: 4 \omega 6$ & $1 \cdot 7$ & $0 \cdot 5$ \\
$20: 5 \omega 3$ & $0 \cdot 1$ & $0 \cdot 1$ \\
$22: 4 \omega 6$ & $0 \cdot 5$ & $0 \cdot 1$ \\
$22: 5 \omega 6$ & $0 \cdot 2$ & Trace \\
$22: 5 \omega 3$ & $0 \cdot 1$ & $0 \cdot 2$ \\
$22: 6 \omega 3$ & $0 \cdot 3$ & $0 \cdot 4$ \\
\hline \hline
\end{tabular}


Table 3. The fatty acid composition (wt \% total fatty acids) of fetal brain phosphoglycerides on day 22 of pregnancy from dams that had been given diets in which the fat was provided by either a soft margarine or a butter-lard mixture

(Results are mean values with their standard errors for eight litters in each group)

\begin{tabular}{|c|c|c|c|c|}
\hline \multirow[b]{2}{*}{ Fatty acid } & \multicolumn{2}{|c|}{ Margarine } & \multicolumn{2}{|c|}{ Butter-lard } \\
\hline & Mean & SE & Mean & SE \\
\hline $16: 0$ & $31 \cdot 8$ & 0.76 & $32 \cdot 2$ & 0.73 \\
\hline $16: 1+17: 0$ & $4 \cdot 4$ & 0.09 & 4.8 & 0.16 \\
\hline $18: 0$ & $16 \cdot 8$ & 0.31 & $16 \cdot 3$ & 0.28 \\
\hline $18: 1$ & $15 \cdot 7^{* *}$ & 0.29 & $17 \cdot 2$ & 0.08 \\
\hline $18: 2 \omega 6+20: 0$ & $1 \cdot 4$ & $0 \cdot 10$ & 1.6 & 0.51 \\
\hline $20: 1$ & 0.6 & 0.12 & 0.7 & 0.09 \\
\hline $20: 2+22: 0$ & 0.4 & 0.11 & 0.5 & 0.06 \\
\hline $20: 3 \omega 6$ & 0.5 & $0 \cdot 11$ & 0.4 & 0.05 \\
\hline $20: 4 \omega 6$ & $12 \cdot 1^{*}$ & 0.23 & $11 \cdot 2$ & 0.18 \\
\hline $20: 5 \omega 3$ & 0.3 & 0.08 & 0.4 & 0.05 \\
\hline $22: 4 \omega 6$ & $2 \cdot 8$ & 0.10 & $2 \cdot 4$ & 0.09 \\
\hline $22: 5 \omega 6$ & $6.7^{* *}$ & 0.33 & $2 \cdot 8$ & 0.14 \\
\hline $22: 5 \omega 3$ & Trace & 0 & Trace & 0 \\
\hline $22: 6 \omega 3$ & $5 \cdot 7^{* *}$ & $0 \cdot 27$ & $9 \cdot 2$ & $0 \cdot 24$ \\
\hline
\end{tabular}

Statistical significance of difference between mean values: ${ }^{*} P<0.05,{ }^{* *} P<0.01$.

Table 4. The fatty acid composition (wt \% total fatty acids) of forebrain phosphoglycerides of 22-d-old pups from dams that had been given diets in which the fat was provided by either a soft margarine or a butter-lard mixture

(Results are mean values with their standard errors for no. of litters shown in parentheses)

\begin{tabular}{|c|c|c|c|c|}
\hline \multirow[b]{2}{*}{ Fatty acid } & \multicolumn{2}{|c|}{ Margarine (11) } & \multicolumn{2}{|c|}{ Butter-lard (9) } \\
\hline & Mean & SE & Mean & SE \\
\hline $16: 0$ & $25 \cdot 8$ & $0 \cdot 14$ & $25 \cdot 2$ & 0.37 \\
\hline $16: 1+17: 0$ & $1 \cdot 0^{* *}$ & 0.02 & $1 \cdot 2$ & 0.04 \\
\hline $18: 0$ & $20 \cdot 1$ & 0.14 & $20 \cdot 2$ & 0.08 \\
\hline $18: 1$ & $14 \cdot 9 * *$ & 0.18 & 16.9 & $0 \cdot 21$ \\
\hline $18: 2 \omega 6+20: 0$ & $2 \cdot 0^{* *}$ & 0.09 & $1 \cdot 2$ & 0.02 \\
\hline $20: 1+18: 3 \omega 3$ & $0.5^{* *}$ & 0.01 & 0.7 & 0.02 \\
\hline $20: 2+22: 0$ & $0.5^{* *}$ & 0.02 & 0.3 & 0.01 \\
\hline $20: 3 \omega 6$ & 0.7 & 0.02 & 0.7 & 0.04 \\
\hline $20: 4 \omega 6$ & $14 \cdot 5^{* *}$ & 0.06 & $13 \cdot 5$ & 0.09 \\
\hline $22: 4 \omega 6$ & $4 \cdot 4^{* *}$ & 0.05 & 3.4 & 0.07 \\
\hline $22: 5 \omega 6$ & $5 \cdot 5^{* *}$ & 0.28 & 1.0 & 0.03 \\
\hline $22: 5 \omega 3$ & $0 \cdot 2^{*}$ & 0.04 & 0.3 & 0.02 \\
\hline $22: 6 \omega 3$ & $10 \cdot 5^{* *}$ & 0.24 & $15 \cdot 5$ & 0.21 \\
\hline
\end{tabular}

Statistical significance of difference between mean values: ${ }^{*} P<0.05, * * P<0.01$.

pup whole brain weights on day 21 post partum (male 1.457 (SE 0.026) $\mathrm{g}$, female 1.442 (SE 0.023 ) $\mathrm{g}$ and male 1.521 (SE 0.035) $\mathrm{g}$, female 1.423 (SE 0.017) $\mathrm{g}$ ) and pup forebrain weights on day 21 post partum (male 1.122 (SE 0.015 ) g, female 1.100 (SE 0.017 ) g and male $1 \cdot 171$ (SE 0.034) g, female 1.100 (SE 0.015) g).

Despite the large differences in the maternal intake of linoleic acid $(18: 2 \omega 6)$ between the two experimental groups, the percentage of $18: 2 \omega 6$ in the brain and retinal phosphoglycerides 
Table 5. The fatty acid composition of (wt \% total fatty acids) of the choline phosphoglycerides $(C P G)$ and the ethanolamine phosphoglycerides $(E P G)$ from the synaptosomes obtained from 21-d-old pups from dams that had been given diets in which the fat was provided by either a soft margarine or a butter-lard mixture

\begin{tabular}{lccccc}
\hline & \multicolumn{2}{c}{ CPG } & & \multicolumn{2}{c}{ EPG } \\
\cline { 2 - 4 } \cline { 5 - 6 } Fatty acid & Margarine & $\begin{array}{c}\text { Butter- } \\
\text { lard }\end{array}$ & & Margarine & $\begin{array}{c}\text { Butter- } \\
\text { lard }\end{array}$ \\
\hline $16: 0$ & $53 \cdot 5$ & $53 \cdot 3$ & & $5 \cdot 7$ & $6 \cdot 6$ \\
$16: 1+17: 0$ & $1 \cdot 7$ & $1 \cdot 7$ & & $0 \cdot 2$ & $0 \cdot 4$ \\
$18: 0$ & $10 \cdot 2$ & $10 \cdot 3$ & & $27 \cdot 7$ & $28 \cdot 1$ \\
$18: 1$ & $18 \cdot 8$ & $21 \cdot 3$ & & $4 \cdot 8$ & $6 \cdot 1$ \\
$18: 2 \omega 6+20: 0$ & $1 \cdot 6$ & $0 \cdot 9$ & & $0 \cdot 5$ & $0 \cdot 3$ \\
$20: 1$ & $0 \cdot 4$ & $0 \cdot 5$ & & $0 \cdot 1$ & $0 \cdot 2$ \\
$22: 0+20: 2$ & $0 \cdot 4$ & $0 \cdot 2$ & & $0 \cdot 1$ & -1 \\
$20: 3 \omega 6$ & $0 \cdot 3$ & $0 \cdot 2$ & & $0 \cdot 3$ & $0 \cdot 3$ \\
$20: 4 \omega 6$ & $8 \cdot 1$ & $7 \cdot 7$ & & $18 \cdot 0$ & $17 \cdot 2$ \\
$22: 4 \omega 6$ & $1 \cdot 0$ & $0 \cdot 7$ & & $8 \cdot 5$ & $6 \cdot 9$ \\
$22: 5 \omega 6$ & $1 \cdot 4$ & $0 \cdot 4$ & & $11 \cdot 0$ & $3 \cdot 3$ \\
$22: 5 \omega 3$ & Trace & $0 \cdot 2$ & & $0 \cdot 3$ & $0 \cdot 4$ \\
$22 ; 6 \omega 3$ & $2 \cdot 7$ & $3 \cdot 5$ & & $23 \cdot 0$ & $30 \cdot 3$ \\
\hline \hline
\end{tabular}

Table 6. The fatty acid composition ( $w t \%$ total fatty acid) of the choline phosphoglycerides $(C P G)$ and the ethanolamine phosphoglycerides (EPG) from the retinas of 21-d-old pups from dams that had been given diets in which the fat was provided by either a soft margarine or a butter-lard mixture

(Results are mean values with their standard errors for no. of litters shown in parentheses)

\begin{tabular}{|c|c|c|c|c|c|c|c|c|}
\hline \multirow[b]{3}{*}{ Fatty acid } & \multicolumn{4}{|c|}{ CPG } & \multicolumn{4}{|c|}{ EPG } \\
\hline & \multicolumn{2}{|c|}{ Margarine (11) } & \multicolumn{2}{|c|}{ Butter-lard (9) } & \multicolumn{2}{|c|}{ Margarine (11) } & \multicolumn{2}{|c|}{ Butter-lard (9) } \\
\hline & Mean & SE & Mean & SE & Mean & SE & Mean & SE \\
\hline $16: 0$ & $32 \cdot 6$ & 0.52 & $32 \cdot 6$ & 0.95 & $5 \cdot 4^{*}$ & $0 \cdot 13$ & 5.0 & 0.12 \\
\hline $16: 1+17: 0$ & $1 \cdot 4$ & 0.03 & 1.6 & $0 \cdot 11$ & 0.3 & 0.03 & 0.4 & $0 \cdot 10$ \\
\hline $18: 0$ & $18 \cdot 0$ & 0.28 & $18 \cdot 1$ & $0 \cdot 37$ & $25 \cdot 3^{* *}$ & $0 \cdot 17$ & $24 \cdot 5$ & 0.24 \\
\hline $18: 1$ & $14 \cdot 9^{* *}$ & 0.23 & 16.9 & $0 \cdot 32$ & $4 \cdot 2$ & $0 \cdot 10$ & $4 \cdot 6$ & $0 \cdot 24$ \\
\hline $18: 2 \omega 6+20: 0$ & $2 \cdot 1^{* *}$ & 0.09 & $1 \cdot 3$ & $0 \cdot 11$ & $1 \cdot 0^{* *}$ & 0.04 & 0.6 & 0.05 \\
\hline $20: 1$ & 0.5 & 0.02 & 0.5 & 0.03 & 0.3 & 0.03 & 0.4 & 0.04 \\
\hline $20: 2+22: 0$ & $0 \cdot 4^{* *}$ & 0.01 & 0.2 & 0.01 & $0 \cdot 3^{* *}$ & 0.01 & $0 \cdot 1$ & 0.01 \\
\hline $20: 3 \omega 6$ & 0.2 & 0.01 & $0 \cdot 2$ & 0.02 & $0.2^{* *}$ & 0.02 & $0 \cdot 2$ & 0.01 \\
\hline $20: 4 \omega 6$ & $10 \cdot 7$ & $0 \cdot 37$ & $9 \cdot 6$ & 0.48 & $14 \cdot 9^{* *}$ & $0 \cdot 30$ & $13 \cdot 6$ & $0 \cdot 20$ \\
\hline $20: 5 \omega 3$ & $0.0^{* *}$ & - & 0.1 & 0.01 & $0 \cdot 0^{* *}$ & - & 0.1 & 0.02 \\
\hline $22: 4 \omega 6$ & $1 \cdot 5^{* *}$ & 0.07 & 0.7 & 0.05 & $5 \cdot 1^{* *}$ & $0 \cdot 14$ & $3 \cdot 2$ & 0.07 \\
\hline $22: 5 \omega 6$ & $4 \cdot 3^{* *}$ & $0 \cdot 30$ & 0.4 & 0.09 & $10 \cdot 7^{* *}$ & 0.76 & $1 \cdot 1$ & $0 \cdot 16$ \\
\hline $22: 5 \omega 3$ & $0 \cdot 3^{* *}$ & 0.02 & 0.6 & 0.03 & $0.6^{* *}$ & 0.02 & $1 \cdot 2$ & 0.05 \\
\hline $22: 6 \omega 3$ & $12 \cdot 4^{* *}$ & 0.45 & $16 \cdot 6$ & $0 \cdot 38$ & $31 \cdot 6^{* * *}$ & 1.07 & 43.9 & 0.69 \\
\hline
\end{tabular}

Statistical significance of difference between mean values: $* P<0.05, * * P<0.01$. 
Table 7. The fatty acid composition ( $w t \%$ total fatty acids) of the forebrain phosphoglycerides of 12-week-old rats, from dams that had been given diets in which the fat was provided by either a soft margarine or a butter-lard mixture, that had been given stock diet from day 21 post partum

(Results are mean values with their standard errors for no. of litters shown in parentheses)

\begin{tabular}{|c|c|c|c|c|}
\hline \multirow[b]{2}{*}{ Fatty acid } & \multicolumn{2}{|c|}{ Margarine (9) } & \multicolumn{2}{|c|}{ Butter-lard (8) } \\
\hline & Mean & $\mathbf{S E}$ & Mean & $\mathbf{S E}$ \\
\hline $16: 0$ & $19 \cdot 3$ & 0.56 & $20 \cdot 5$ & $0 \cdot 29$ \\
\hline $16: I+17: 0$ & $0 \cdot 6$ & 0.04 & 0.7 & 0.02 \\
\hline $18: 0$ & $21 \cdot 3$ & $0 \cdot 27$ & $21 \cdot 3$ & 0.40 \\
\hline $18: 1$ & $24 \cdot 2$ & $0 \cdot 34$ & 23.4 & 0.56 \\
\hline $18: 2 \omega 6+20: 0$ & $0 \cdot 8$ & $0 \cdot 04$ & 0.7 & 0.06 \\
\hline $20: 1+18: 3 \omega 3$ & $2 \cdot 4$ & 0.09 & $2 \cdot 3$ & 0.08 \\
\hline $20: 2+22: 0$ & $0.5^{*}$ & 0.06 & 0.3 & 0.03 \\
\hline $20: 3 \omega 6$ & 0.6 & 0.05 & 0.6 & 0.02 \\
\hline $20: 4 \omega 6$ & $11 \cdot 1$ & $0 \cdot 16$ & $11 \cdot 0$ & $0 \cdot 13$ \\
\hline $22: 4 \omega 6$ & $3 \cdot 3$ & $0 \cdot 14$ & $3 \cdot 2$ & 0.07 \\
\hline $22: 5 \omega 6$ & $0.5^{* *}$ & 0.03 & $0 \cdot 3$ & 0.06 \\
\hline $22: 5 \omega 3$ & $0 \cdot 1$ & 0.02 & $0 \cdot 2$ & 0.01 \\
\hline $22: 6 w 3$ & $15 \cdot 1$ & $0 \cdot 20$ & $15 \cdot 5$ & $0 \cdot 30$ \\
\hline
\end{tabular}

Statistical significance of difference between mean values: $* P<0.05, * * P<0.01$.

was similarly low (Tables 3-6). The percentage of $18: 2 \omega 6$, however, was only statistically significantly greater in the 21 -d-old pups from the margarine-fed group compared with the butter-lard-fed group. This was not unexpected since $18: 2 \omega 6$ is only a minor constituent of brain lipids. Differences were, however, noted in the percentages of $\mathrm{C}_{22}$ derivatives of the $\omega 6$ and $\omega 3$ series between the two groups. The percentage of 22:6 $\omega 3$ was much greater in both the fetuses and the pups from the animals given the butter-lard mixture. The deficit in 22:6 33 in the margarine-fed group was compensated for by higher percentages of

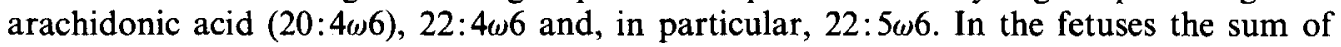
$22: 6 \omega 3+22: 5 \omega 6$ was $12.0 \%$ in the margarine-fed group and $12.5 \%$ in the butter-lard-fed group, whereas the corresponding values in the pups were $16.0 \%$ and $16.4 \%$ respectively. This difference between the balance of $\mathrm{C}_{22}$ derivatives was best illustrated by the fatty acid composition of the synaptosomal and retinal ethanolamine phosphoglycerides (Tables 5 and 6). Docosahexaenoic acid accounted for almost half the total fatty acids in the retinal ethanolamine phosphoglycerides of the pups from the butter-lard-fed group.

It was surprising to find that the differences in the fatty acid composition of the forebrain phosphoglycerides were barely discernable between the two groups 9 weeks after the 21-d-old pups had been transferred from the experimental to the stock diet: the percentage of 22:6 $\omega 3$ was similar but that of $22: 5 \omega 6$ was still statistically significantly greater in those which came from the margarine-fed group (Table 7).

\section{DISCUSSION}

Our results show that the substitution of a soft margarine rich in linoleic acid for a mixture of butter and lard as the only source of fat in the maternal diet leads to a decrease in the

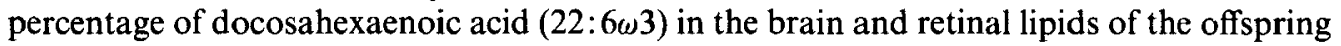
and that this change is accompanied by a compensatory increase in the percentage of docosapentaenoic acid $(22: 5 \omega 6)$. 
It is tempting to attribute the lower percentage of $22: 6 \omega 3$ to a lower maternal intake of $18: 3 \omega 3$. However, the amount of $18: 3 \omega 3$ provided by the margarine diet was considerably greater than the amounts provided by diets designed to result in linolenic acid deficiency. For example, in the studies of Tinoco et al. (1979) the diet provided $38 \mathrm{mg}$ of $18: 3 \omega 3 / \mathrm{kg}$ diet compared with $1032 \mathrm{mg} / \mathrm{kg}$ provided by our margarine diet. Alling et al. (1972) showed similar percentages of 22:6 $\omega 3$ in brain ethanolamine phosphoglycerides from 21-d-old pups from Sprague-Dawley dams that had been given $0.85 \%$ as $18: 2 \omega 6$ and $0.15 \%$ as $18: 3 \omega 3$ of the total energy intake compared with those given $4.25 \%$ and $0.75 \%$ respectively. Moreover, owing to the short duration of the present study, the animals given the margarine

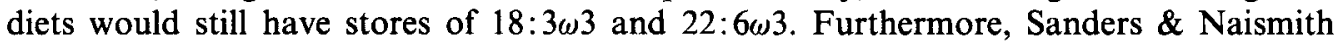
(1980a) were able to show a similarly low percentage of $22: 6 \omega 3$ in the brain phosphoglycerides from fetuses from mothers that had been given a diet during pregnancy which provided $29.7 \%$ of the energy intake as $18: 2 \omega 6$ and $0.5 \%$ as $18: 3 \omega 3$; a far greater amount

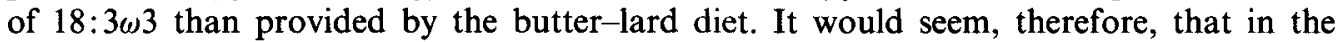
absence of $22: 6 \omega 3$ from the diet it is the intake of $18: 2 \omega 6$ relative to $18: 3 \omega 3$ that is the major factor determining the percentage of $22: 6 \omega 3$ in pup brain lipids.

The fetal (Sanders \& Naismith, 1980 b) and the new born rat pup (Dhopeshwarker \& Subramaniam, 1976; Dwyer \& Bernsohn, 1979) has a high capacity to convert $18: 3 \omega 3$ to 22:6 63 which renders it susceptible to competitive inhibition by an excess of linoleic acid. The activity of $\Delta 6$ desaturase in rat brain apparently declines rapidly postnatally (Strouve-

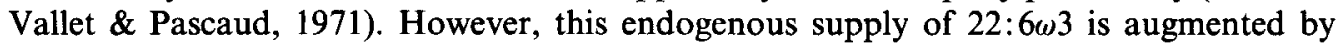
preformed 22:6 3 in the maternal milk (Sinclair, 1975). The milk curd of the group given the margarine diet contained a substantial amount of $22: 6 \omega 3$ in relation to the amount needed by the developing brain, although it was less than in the group that received the animals fats. This might explain why the percentage of $22: 6 \omega 3$ in the brain phosphoglycerides did not fall postnatally in the margarine-fed group.

It was surprising that the quite large differences in the percentages of 22:6 63 and $22: 5 \omega 6$ in the brain phosphoglycerides that were observed between the two groups $21 \mathrm{~d}$ postnatally were barely discernible 9 weeks after both groups had been given the same stock diet. This shows that changes in brain fatty acid composition induced by the margarine diet could

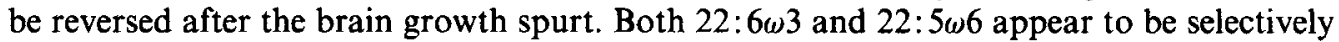
incorporated into the membrane lipids of the synapses and retina, specifically the synaptosomal vesicles (Breckenridge \& Gombos, 1971) and the rod outer segments (Anderson et al. 1977). This would imply that these tissues have a requirement for either $22: 5 \omega 6$ or 22:6 63 .

The stock diet, unlike the experimental diets, contained significant amounts of preformed $20: 5 \omega 3$ and $22: 6 \omega 3$ in addition to $18: 3 \omega 3$. Using radioactively-labelled fatty acids, Sinclair (1975) showed that the uptake of dietary $22: 6 \omega 3$ by brain was very high compared with

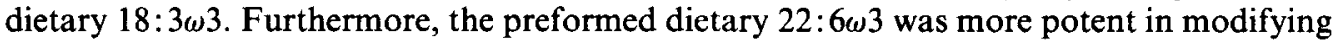
tissue lipids than was dietary $18: 3 \omega 3$. This can be explained by the inefficient conversion of $18: 3 \omega 3$ to $22: 6 \omega 3$ and the high affinity of certain phosphoglycerides for $22: 6 \omega 3$.

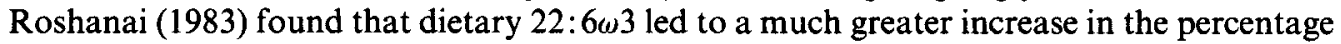

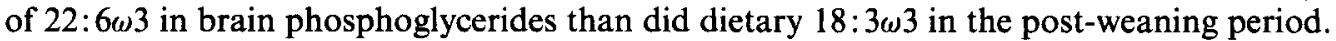

Conclusive proof for the essentiality of linolenic acid in mammals is lacking. The key question is whether the replacement of $22: 6 \omega 3$ by $22: 5 \omega 6$ in brain and retinal lipids matters. Differences in synaptic (Bernsohn \& Spitz, 1974) and retinal function (Wheeler et al. 1975) could explain the behavioural abnormalities found in association with a low percentage of

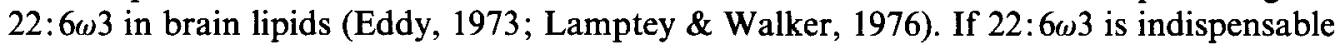
then the essentiality of linolenic acid hinges upon the extent to which it can be converted to $22: 6 \omega 3$. This conversion occurs readily in the rat; however, in other species this capacity 
may be limited, for example in the cat (Rivers et al. 1975). Man can certainly convert 18:3 33 to $20: 5 \omega 3$ but the capacity to convert $18: 3 \omega 3$ to $22: 6 \omega 3$ does appear to be limited (Sanders et al. 1978; Sanders \& Younger, 1981). This might imply that preformed dietary $22: 3 \omega 3$ may

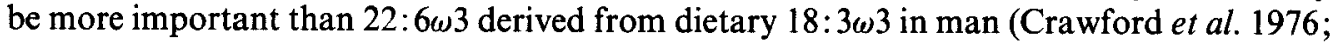
Putnam et al. 1982). However, high intakes of linoleic acid do also suppress the conversion of 18:3 $\omega 3$ to $20: 5 \omega 3$ in man (Sanders \& Younger, 1981).

The relevance of this study to human nutrition may be questioned because margarine is never the only source of fat in the diet. However, the fatty acid composition of the margarine used does reflect the quality of fat advocated for the prevention of coronary heart disease. Moreover, the level of fat in experimental diets was similar to that found in human diets. Differences in placental fatty acid transport and the timing of the phases of brain growth in relation to birth can make comparison among species difficult; for example in the rat the brain growth spurt occurs postnatally, in man perinatally and in the guinea-pig prenatally (Dobbing, 1972). Nevertheless, Pavey (1979) observed a similar decrease in the percentage of 22:6 33 in the brain phosphoglycerides of fetuses of guinea-pigs from mothers that were given a diet in which the fat was provided by maize oil compared with one in which the fat was provided by beef tallow. Although we were able to show that the percentage of 22:6 63 could be increased after the period of rapid brain growth, it is likely that if a mother is consuming a diet rich in 18:2 $\omega 6$ and almost devoid of $22: 6 \omega 3$ then her offspring would be weaned on to a similar diet. Indeed, Sanders et al. (1978) found very low levels of 22: $6 \omega 3$ in the erythrocyte lipids of infants that had been born of and breast-fed

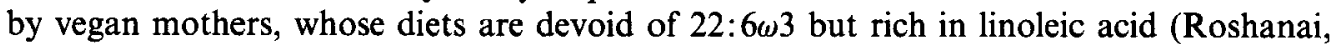
1983), and in vegan children. The implications of a change in the balance of dietary polyunsaturated fatty acids on brain and retinal fatty acid composition deserve consideration in man especially when dietary recommendations are made for the whole community.

The authors are grateful to the Rank Prize Funds for a grant and to $\mathrm{Mr} \mathrm{W}$. Gunn for the GLC-mass spectroscopy.

\section{REFERENCES}

Ackman, R. G. (1969). In Methods in Enzymology, vol. 14, pp. 329-391 [J. M. Lowenstein, editor]. New York: Academic Press.

Alling, C., Bruce, A., Karlsson, I., Sapia, O. \& Svennerholm, L. (1972). Journal of Nutrition 102, 773-782.

Alling, C., Bruce, A., Karlsson, I. \& Svennerholm, L. (1974). Journal of Neurochemistry 23, $1263-1270$.

Anderson, R. E., Benolken, R. M., Jackson, M. B. \& Maude, M. B. (1977). In Advances in Experimental Medicine and Biology, vol. 83, pp. 547-559. [N. G. Bazan, R. R. Brenner and N. M. Guisto, editors]. London: Plenum Press.

Bernsohn, J. \& Spitz, F. J. (1974). Biochemistry Biophysics Research Communications 57, 293-298.

Breckenridge, W. C. \& Gombos, G. I. G. (1971). Brain Research 33, 581-582.

Crawford, M. A., Hall, B., Lawrence, B. M. \& Munhambo, A. (1976). Current Medical Research and Opinion 4 (Suppl. 1), 33-43.

Dhopeshwarker, G. A. \& Subramaniam, C. (1976). Lipids 11,67-71.

Dobbing, J. (1972). In Lipids, Malnutrition and the Developing Brain, pp. 9-30 [K. Elliot and J. Knight, editors]. Amsterdam: Elsvier.

Dwyer, B. E. \& Bernsohn, J. (1979). Biochimica Biophysica Acta 575, 309-317.

Eddy, D. E. (1973). Dietary fat influences on brain and liver fatty acid composition: importance of docosahexaenoic acid (22:6w3). PhD Thesis, University of Nebraska.

Galli, C., Trzeciak, H. I. \& Paoletti, R. (1971). Biochimica Biophysica Acta 248, 449-454.

Lamptey, M. S. \& Walker, B. L. (1976). Journal of Nutrition 106, 86-93.

Mohrhauer, H. \& Holman, R. T. (1963). Journal of Neurochemistry 10, 523-530.

Morgan, I. G., Wolfe, L. S., Mandel, I. P. \& Gombos, G. (1971). Biochimica Biophysica Acta 241, 737-751.

Paul, A. A. \& Southgate, D. A. T. (1978). McCance and Widdowson's The Composition of Foods. London: H.M. Stationery Office.

Pavey, D. E. (1979). Influence of dietary fat on fatty acid composition of body lipids in early life. PhD Thesis, University of Cambridge. 
Putnam, J. C., Carlson, S. E., Devoe, P. W. \& Barness, L. A. (1982). American Journal of Clinical Nutrition 36, $106-114$.

Rahm, J. J. \& Holman, R. T. (1964). Journal of Nutrition 84, 15-19.

Rivers, J. P. W., Sinclair, A. J. \& Crawford, M. A. (1975). Nature 258, 171-173.

Roshanai, F. (1983). The influence of dietary $\omega 3$ polyunsaturated fatty acids on vascular lipids and platelet function. PhD Thesis, University of London.

Royal College of Physicians/British Cardiac Society (1976). Journal of the Royal College of Physicians 10, $213-263$.

Sanders, T. A. B., Ellis, F. R. \& Dickerson, J. W. T. (1978). American Journal of Clinical Nutrition 31, $805-813$.

Sanders, T. A. B. \& Naismith, D. J. (1979). Proceedings of the Nutrition Society 39, 80A.

Sanders, T. A. B. \& Naismith, D. J. (1980a). British Journal of Nutrition 44, 205--208.

Sanders, T. A. B. \& Naismith, D. J. (1980 b) Proceeding of Nutrition Society 39, 80 A.

Sanders, T. A. B., Vickers, M. \& Haines, A. P. (1981). Clinical Science 61, 317-324.

Sanders, T. A. B. \& Younger, K. M. (1981). British Journal of Nutrition 45, 613-616.

Sinclair, A. J. (1975). Lipids 9, 809-819.

Strouve-Vallet, C. \& Pascaud, M. (1971). Biochemie 53, 699-703.

Tinoco, J., Babcock, R., Hincenbergs, I., Medwadowski, B. \& Miljanich, P. (1979). Lipids 13, 6-17.

Wheeler, T. G., Benolken, R. M. \& Anderson, R. E. (1975). Science (New York) 188, 1312-1314. 